\title{
A EVASÃO NO ENSINO SUPERIOR BRASILEIRO
}

\section{ROBERTO LEAL LOBO E SILVA FILHO \\ PAULO ROBERTO MOTEJUNAS \\ OSCAR HIPÓLITO \\ MARIA BEATRIZ DE CARVALHO MELO LOBO}

Instituto Lobo para o Desenvolvimento da Educação, da Ciência e da Tecnologia
rllobo@loboeassociados.com.br

\begin{abstract}
RESUMO
Neste trabalho a evasão nas instituições de educação superior no Brasil é estudada com base em dados oficiais, em que se incluem análises regionais dos índices da evasão anual média e da evasão por tipo de instituição. Verifica-se uma correlação negativa entre os índices de evasão e a demanda por curso. Com vistas a possibilitar comparações, são apresentados dados internacionais que indicam que a evasão no Brasil não difere muito das médias internacionais.

ENSINO SUPERIOR - EVASÃO ESCOLAR - BRASIL
\end{abstract}

\begin{abstract}
HIGHER EDUCATION INSTITUTIONS' EVASION. In this work, evasion in institutions of higher education is studied, based on official data, including regional analyses of annual mean evasion rates and evasion rates by type of institution. It was verified that there is a negative correlation between evasion rates an demand for undergraduate courses. Comparisons with international data are presented, pointing out that the evasion rates in Brazil do not differ a lot from those of other countries.

HIGHER EDUCATION - DROPPING OUT - BRAZIL
\end{abstract}


A evasão é, certamente, um dos problemas que afligem as instituições de ensino em geral. A busca de suas causas tem sido objeto de muitos trabaIhos e pesquisas educacionais.

A evasão estudantil no ensino superior é um problema internacional que afeta o resultado dos sistemas educacionais. As perdas de estudantes que iniciam mas não terminam seus cursos são desperdícios sociais, acadêmicos e econômicos. No setor público, são recursos públicos investidos sem o devido retorno. No setor privado, é uma importante perda de receitas. Em ambos os casos, a evasão é uma fonte de ociosidade de professores, funcionários, equipamentos e espaço físico.

Enquanto no setor privado de $2 \%$ a $6 \%$ das receitas das instituições de ensino superior - IES - são despendidos com marketing para atrair novos estudantes, nada parecido é investido para manter os estudantes já matriculados.

Além disso, são raríssimas as IES brasileiras que possuem um programa institucional profissionalizado de combate à evasão, com planejamento de ações, acompanhamento de resultados e coleta de experiências bem-sucedidas. A evasão deve ser entendida sob dois aspectos similares, mas não idênticos:

I. A evasão anual média mede qual a percentagem de alunos matriculados em um sistema de ensino, em uma IES, ou em um curso que, não tendo se formado, também não se matriculou no ano seguinte (ou no semestre seguinte, se o objetivo for acompanhar o que acontece em cursos semestrais). Por exemplo. se uma IES tivesse 100 alunos matriculados em certo curso que poderiam renovar suas matrículas no ano seguinte, mas somente 80 o fizessem, a evasão anual média no curso seria de $20 \%$.

2. A evasão total mede o número de alunos que, tendo entrado num determinado curso, IES ou sistema de ensino, não obteve o diploma ao final de um certo número de anos. É o complemento do que se chama índice de titulação. Por exemplo, se 100 estudantes entraram em um curso em um determinado ano e 54 se formaram, o índice de titulação é de $54 \%$ e a evasão nesse curso é de $46 \%$.

Os dois conceitos estão ligados, mas não diretamente, porque depende dos níveis de reprovação e das taxas de evasão por ano, ao longo do curso, 
que não são as mesmas. Verifica-se, em todo o mundo, que a taxa de evasão no primeiro ano de curso é duas a três vezes maior do que a dos anos seguintes. Esse é um problema muito estudado no exterior e influi na relação entre evasão anual e índice de titulação.

Outra questão importante, diz respeito às bases financeiras da evasão. De modo geral, as instituições, públicas e privadas, dão como principal razão da evasão a falta de recursos financeiros para o estudante prosseguir nos estudos. É, também, o que o estudante declara quando perguntado sobre a principal razão da evasão.

No entanto, verifica-se nos estudos existentes que essa resposta é uma simplificação, uma vez que as questões de ordem acadêmica, as expectativas do aluno em relação à sua formação e a própria integração do estudante com a instituição constituem, na maioria das vezes, os principais fatores que acabam por desestimular o estudante a priorizar o investimento de tempo ou financeiro, para conclusão do curso. Ou seja, ele acha que o custo benefício do "sacrifício" para obter um diploma superior na carreira escolhida não vale mais a pena.

O Brasil tem poucos estudos sistemáticos e dados nacionais sobre evasão. Por esse motivo, o Instituto Lobo para o Desenvolvimento da Educação, da Ciência e da Tecnologia decidiu realizar um trabalho de coleta e organização de dados sobre a evasão brasileira, acrescentando dados internacionais para comparação, no intuito de contribuir com a comunidade acadêmica brasileira para o aprofundamento dos estudos sobre tema tão relevante.

O Instituto Nacional de Estudos e Pesquisas Educacionais - Inep -, órgão do Ministério da Educação, tem divulgado publicamente, de forma regular, dados referentes aos matriculados, ingressantes e egressos do ensino superior. Suas sinopses têm, nos últimos anos, uma formatação padronizada, sistemática, que permite o uso de uma série de dados anuais, gerando a possibilidade de analisá-los em termos de evolução de indicadores ao longo de um período significativo de anos.

Este estudo apresenta dados, análises e comentários gerais sobre a evasão no ensino superior brasileiro, envolvendo, em uma parte do trabalho, o período de 2000 a 2005 e, na outra, o estudo da evasão dos diferentes cursos de graduação no período de 200 I a 2005 a partir dos dados do Inep.

Os dados sobre evasão nos cursos superiores do Brasil não diferem muito das médias internacionais, variam bastante por dependência administrativa (pública ou privada), região e curso. 


\section{A EVASÃO, SEU ESTUDO E METODOLOGIA}

A evasão pode ser medida em uma instituição de ensino superior, em um curso, em uma área de conhecimento, em um período de oferta de cursos e em qualquer outro universo, desde que tenhamos acesso a dados e informações pertinentes. Em princípio, pode-se estudar a evasão no âmbito de uma IES, ou em um sistema, ou seja, um conjunto de instituições.

O estudo interno, realizado por uma IES com base em seus dados, pode ser muitas vezes mais detalhado porque é possível institucionalizar-se um mecanismo de acompanhamento da evasão, registrando os diversos casos, agrupando e analisando subgrupos, ou diferentes situações (cancelamento, trancamento, transferência, desistência, por exemplo) e, a partir daí, organizar tabelas e gráficos que demonstrem a evolução da evasão para buscar formas de combatê-la com fundamento nos resultados.

Numa IES, a evasão pode ser medida pela simples organização das informações disponíveis nos setores de registro e controle acadêmico. É possível até medir a evasão em uma turma pela comparação entre o número de ingressantes no ano de formação dessa turma e o número de concluintes do mesmo grupo de alunos.

Neste trabalho a idéia é o estudo macroscópico da evasão. Com os dados disponibilizados pelo Inep em suas Sinopses do Ensino Superior, foram organizados tabelas e gráficos em que se mostra a evolução da evasão no Brasil de acordo com os seguintes agrupamentos:

- no conjunto de todas as IES;

- por forma de organização acadêmica;

- por categoria administrativa;

- por região geográfica;

- por área do conhecimento e por cursos'.

O estudo da evasão por área do conhecimento e por cursos foi feito com dados do período entre 2000 e 2005 e as evasões, calculadas para os anos entre 200 I e 2005.

I. Foram analisados 47 cursos e as tabelas 7 e 8 reportam aqueles com, respectivamente, as maiores e menores taxas de evasão. 
Os demais estudos de evasão levaram em conta os dados do período entre 1999 e 2005 e foram calculadas as evasões entre 2000 e 2005.

Como os dados do Inep são obrigatoriamente agregados, não é possível acompanhar a evasão por uma coorte representada pelo acompanhamento individual dos alunos. Assim sendo, utiliza-se, como cálculo básico desse estudo, a comparação entre o número de alunos que estavam matriculados num determinado ano, subtraídos os concluintes, com a quantidade de alunos matriculados no ano seguinte, subtraindo-se deste último total os ingressantes desse ano. Assim, mede-se a perda de alunos de um ano para outro: a evasão anual.

O cálculo do percentual da evasão referente ao ano n é dado por:

$$
E(n)=I-[M(n)-I(n)] /[M(n-I)-C(n-I)],(I)
$$

onde $E$ é evasão, $M$ é número de matriculados, $C$ é o número de concluintes, I é o número de ingressantes, $n$ é o ano em estudo e ( $n-l)$ é o ano anterior. Esta forma de cálculo é mais exata do que a utilizada em alguns trabalhos internacionais e será objeto de futura publicação.

\section{CENÁRIO DO ENSINO SUPERIOR NO BRASIL EM 2005}

Antes de apresentar tabelas referentes ao estudo da evasão, é conveniente descrever o cenário do ensino superior no Brasil em 2005, último ano do período em análise.

A tabela I mostra a distribuição, para o ano de 2005, do número e percentual de instituições de ensino superior, de cursos de graduação oferecidos e de matrículas separadas por categoria administrativa: privadas ou públicas, e por forma de organização acadêmica: universidades, centros universitários e faculdades, lembrando que o termo faculdades agrupa o conjunto nomeado pelo Inep como faculdades, faculdades integradas, institutos, escolas e centros de educação tecnológica.

O Brasil tinha, em 2005 - data da última sinopse divulgada pelo Inep -, 2.I65 IES, das quais 89,3\%, ou seja, 1.934, eram privadas. A predominância é de faculdades privadas, que representam $80,24 \%$ do total de IES. Embora haja nove vezes mais IES privadas que públicas, o número de universidades privadas é quase o mesmo que o de universidades públicas. 
TABELA I

CENÁRIO DO ENSINO SUPERIOR NO BRASIL EM 2005

\begin{tabular}{|c|c|c|c|c|c|c|c|c|c|c|}
\hline \multirow{2}{*}{\multicolumn{2}{|c|}{$\begin{array}{l}\text { Tipo de Instituição de } \\
\text { Ensino Superior ( IES ) }\end{array}$}} & \multicolumn{2}{|c|}{ IES } & \multicolumn{2}{|c|}{ Cursos } & \multicolumn{2}{|l|}{ Alunos } & \multicolumn{3}{|c|}{ Razões } \\
\hline & & $N$ & $\%$ & $\mathrm{~N}$ & $\%$ & $\mathrm{~N}$ & $\%$ & $\begin{array}{c}\text { Cursos/ } \\
\text { IES }\end{array}$ & $\begin{array}{c}\text { Alunos/ } \\
\text { IES }\end{array}$ & $\begin{array}{l}\text { Alunos/ } \\
\text { Curso }\end{array}$ \\
\hline TTtais & & & Pी & & & & & 9 & 2057 & 210 \\
\hline \multirow{4}{*}{ Públicas } & Unive & 90 & 42 & 5412 & 26,5 & 1042816 & 230 & 60 & 1587 & 193 \\
\hline & Centro Universitário & 3 & 0,1 & 43 & 0,2 & | 5.757 & 0,0 & 14 & 5.252 & 366 \\
\hline & Faculdade & 138 & 6,4 & 736 & 3,6 & 133616 & 3,0 & 5 & 968 & 182 \\
\hline & Total & 231 & 10,7 & 6.191 & 30,3 & 1.192 .189 & 27,0 & 27 & 5.161 & 193 \\
\hline \multirow{4}{*}{ Privadas } & Universidade & 86 & 4,0 & 5.480 & 26,9 & 1.426 .962 & 32,0 & 64 & 16593 & 260 \\
\hline & Centro Universitário & 111 & 5,1 & 2.499 & 12,2 & 659.170 & 15,0 & 23 & 5.938 & 264 \\
\hline & Faculdade & 1.737 & 80,2 & 6237 & 30,6 & I. 174.835 & 26,0 & 4 & 676 & 188 \\
\hline & Total & 1.934 & 89,3 & 14.216 & 69,7 & 3.260 .967 & 73,0 & 7 & 1.544 & 210 \\
\hline
\end{tabular}

Fonte: Inep: Sinopse do Ensino Superior - 2005 (Brasil, 2006).

As 2. 165 IES brasileiras ofereciam um total de 20.407 cursos de graduação presenciais, sendo que $69,7 \%$, ou mais de $2 / 3$ deles, eram oferecidos por IES privadas. As universidades públicas ofereciam $26,5 \%$ dos cursos, índice semelhante aos $26,9 \%$ oferecidos pelas universidades privadas, que perdiam, ainda, para o conjunto de faculdades privadas, as quais respondiam por $30,6 \%$ do total.

As universidades privadas tinham 32\% dos alunos matriculados em 2005, contra 23\% das universidades públicas.

A tabela I mostra, ainda, as relações cursos/IES, alunos/IES e alunos/ curso.

Na média, as universidades públicas oferecem 60 cursos cada uma e as privadas 64 , enquanto as universidades privadas têm mais alunos por IES que as públicas.

Esse conjunto de dados mostra que existe no ensino superior brasileiro uma predominância quantitativa das instituições privadas, o que permite inferir que os dados referentes aos alunos das IES privadas afetam de forma decisiva os indicadores globais do ensino superior brasileiro, inclusive a evasão.

A tabela 2 mostra a distribuição percentual das matrículas por área do conhecimento e por categoria - pública ou privada - da IES. 
TABELA 2

DISTRIBUIÇÃO PERCENTUAL DE MATRÍCULAS POR ÁREA

DE CONHECIMENTO E POR IES PÚBLICAS E PRIVADAS - 2005

\begin{tabular}{lcc}
\hline Área de conhecimento & Publica & Privada \\
\hline Educação & 42 & 58 \\
Humanidades e Artes & 43 & 57 \\
Ciências Sociais, Negócios e Direito & 14 & 86 \\
Ciências, Matemática e Computação & 35 & 65 \\
Engenharia, Produção e Construção & 44 & 56 \\
Agricultura e Veterinária & 59 & 41 \\
Saúde e Bem-Estar Social & 21 & 79 \\
Serviços & 13 & 87 \\
\hline Total & 28 & 72
\end{tabular}

Fonte: Cálculo baseado nos dados do Inep: Sinopse do Ensino Superior - 2005 (Brasil, 2006).

Observa-se que apenas na área de Agricultura e Veterinária as públicas têm mais alunos que as privadas, sendo que nas áreas de Ciências Sociais, Negócios e Direito, Saúde e Bem-Estar Social e Serviços, a predominância de matrículas nas IES privadas é bem acentuada e nas demais áreas a distribuição é mais equilibrada, embora ainda com maioria nas IES privadas.

\section{EVASÃO ANUAL POR CATEGORIA ADMINISTRATIVA E FORMA DE ORGANIZAÇÃO}

\section{Brasil}

A evasão anual média entre 2000 a 2005, para o conjunto formado por todas as IES do Brasil, foi calculada com base na fórmula ( I ) e é apresentada na tabela 3 , a qual indica que ela foi de $22 \%$.

\section{Evasão nas IES públicas e privadas}

A evasão anual nas IES públicas tem oscilado em torno dos I $2 \%$, variando entre 9 e $15 \%$ no período, enquanto as IES privadas mostram uma oscilação em torno de $26 \%$, contra uma taxa nacional típica de 22\%. Obviamente, como 
TABELA 3

COMPARAÇÃO ENTRE AS EVASÕES ANUAIS MÉDIAS

NAS IES DO BRASIL, POR CATEGORIA ADMINISTRATIVA

\begin{tabular}{lccccccc}
\hline Categoria administrativa & 2000 & 2001 & 2002 & 2003 & 2004 & 2005 & Média \\
\hline Públicas & 13 & 14 & 9 & 10 & 15 & 12 & 12 \\
Federais & 9 & 14 & 11 & 9 & 14 & 10 & 11 \\
Estaduais & 11 & 12 & 9 & 10 & 15 & 11 & 12 \\
Municipais & 40 & 18 & -2 & 6 & 19 & 20 & 17 \\
Privadas & 22 & 26 & 27 & 28 & 28 & 25 & 26 \\
Particulares & 9 & 24 & 27 & 27 & 29 & 27 & 24 \\
Comum. e Conf. & 31 & 28 & 27 & 28 & 26 & 24 & 27 \\
Brasil & 19 & 22 & 21 & 22 & 24 & 22 & 22 \\
\hline
\end{tabular}

Fonte: Cálculo baseado nos dados do Inep: Sinopses do Ensino Superior - 200 I-2005 (Brasil, 2006).

as IES privadas detêm a maioria dos alunos no ensino superior, seu peso é maior e a média nacional está mais próxima de seus índices.

\section{IES públicas e privadas: detalhamento}

A tabela 3 possibilita ainda uma comparação das evasões anuais médias das IES públicas federais, estaduais e municipais e das IES privadas, particulares, comunitárias e confessionais com as do Brasil em geral.

Pode-se perceber que as IES federais e estaduais seguem, de certa forma, o padrão das IES públicas. Já as municipais mostram um comportamento anômalo, e uma análise mais detalhada foge ao escopo deste trabalho, uma vez que envolveria a obtenção de mais informações sobre esse conjunto. Os dados disponibilizados nos Censos do Inep não permitem o estabelecimento de qualquer tipo de correlação que propicie entender a anomalia. As IES particulares, por sua vez, assim como as comunitárias e confessionais obedecem ao padrão das privadas, com algumas oscilações, mas destoa do conjunto a evasão das particulares em 2000, que foi de apenas 9\%. Os dados mostram que de 1999 para 2000 o número de matrículas desse conjunto cresceu a uma taxa maior que a de ingressantes, fazendo crer que houve incorporação de alunos transferidos ou com aproveitamento de estudos sem que estes tenham sido contabilizados como ingressantes. 


\section{Evasão no Brasil por forma de organização acadêmica}

A tabela 4 possibilita a comparação entre as taxas de evasão anual média dos diferentes tipos de IES de acordo com a forma de organização acadêmica.

As universidades mantiveram, no período estudado, uma taxa de evasão anual em torno de 19\%, abaixo da média nacional, de 22\%. Os centros universitários, por sua vez, mostraram um desempenho muito oscilante, mas, no conjunto, estiveram quase sempre abaixo da média brasileira. Já as faculdades se mantiveram com uma taxa de evasão anual sempre acima da média nacional e mesmo acima dos valores observados para o conjunto de IES privadas. Pode-se afirmar que um segmento responsável pela elevação das taxas nacionais de evasão é o conjunto de faculdades.

TABELA 4

COMPARAÇÃO DA EVASÃO ANUAL MÉDIA NAS IES

DO BRASIL, POR FORMA DE ORGANIZAÇÃO ACADÊMICA

\begin{tabular}{lccccccc}
\hline $\begin{array}{l}\text { Forma de organização } \\
\text { academica }\end{array}$ & 2000 & 2001 & 2002 & 2003 & 2004 & 2005 & Média \\
\hline Universidades & 16 & 20 & 18 & 20 & 22 & 18 & 19 \\
Centros Universitários & 9 & 17 & 21 & 25 & 16 & 24 & 19 \\
Faculdades & 28 & 31 & 30 & 27 & 33 & 27 & 29 \\
Brasil & 19 & 22 & 21 & 22 & 24 & 22 & 22 \\
\hline
\end{tabular}

Fonte: Cálculo baseado nos dados do Inep: Sinopses do Ensino Superior - 200 I-2005 (Brasil, 2006).

TABELA 5

COMPARAÇÃO ENTRE AS EVASÕES ANUAIS MÉDIAS

NAS IES DO BRASIL, POR REGIÃO GEOGRÁFICA

\begin{tabular}{lccccccc}
\hline Região Geográfica & 2000 & 2001 & 2002 & 2003 & 2004 & 2005 & Média \\
\hline Norte & 18 & 14 & 15 & 10 & 21 & 16 & 16 \\
Nordeste & 14 & 23 & 21 & 20 & 25 & 21 & 21 \\
Sudeste & 20 & 21 & 22 & 24 & 25 & 22 & 22 \\
Sul & 20 & 24 & 23 & 23 & 23 & 21 & 22 \\
Centro-Oeste & 20 & 27 & 19 & 23 & 26 & 25 & 23 \\
Brasil & 19 & 22 & 21 & 22 & 24 & 22 & 22 \\
\hline
\end{tabular}

Fonte: Cálculo baseado nos dados do Inep: Sinopses do Ensino Superior - 200 I-2005 (Brasil, 2006). 


\section{EVASÃO POR REGIÃO GEOGRÁFICA}

A tabela 5 mostra a comparação entre as taxas médias anuais de evasão das regiões geográficas e as verificadas no país como um todo.

Na Região Norte, cerca de 60\% dos alunos matriculados em 2005 eram de IES de natureza pública, o que é coerente com o fato da taxa de evasão se aproximar mais daquela observada nesse tipo de IES. A taxa oscilou bastante no período, mas foi bem menor que a nacional.

Utilizando-se os dados do Inep para cada estado da Região Norte no período de 2000 a 2005, observa-se que, se a Região Norte como um todo tem uma evasão média anual menor que a do país, cada estado teve sua evasão anual variando de forma completamente distinta do que ocorreu no país como um todo no mesmo período.

Os estados da Região Norte passaram, no período em estudo, por grande mudança quantitativa no ensino superior. Com a criação de IES e de cursos que oferecem um número razoável de vagas, é muito provável que, em um primeiro momento, tenha havido um crescimento do número de matrículas e de ingressantes afetado pela demanda interna até então reprimida, e pela atração de contingentes expressivos de alunos oriundos de outras regiões do país, particularmente em áreas com demanda reprimida. Toda essa movimentação gerou uma evolução que difere, com exceção do verificado no Estado do Pará, do observado no país como um todo.

Certamente todo o sistema de ensino superior, em vários desses estados, está na fase inicial de expansão e aos poucos irá se ajustando ao perfil normal de evolução, que acompanha o crescimento da população².

A Região Nordeste também mostrou oscilações na taxa de evasão, ficando acima em alguns anos e, em outros, abaixo da média nacional. Dados do Inep revelam que todos os estados do Nordeste tiveram a taxa de evasão anual oscilante ao longo do período em análise. No entanto, as oscilações verificadas no Piauí e no Maranhão são mais intensas e por isso seus dados não foram utilizados nos estudos de correlação da evasão com outros indicadores.

2. Devido às grandes oscilações dos valores da evasão em alguns estados da Região Norte, eles não foram considerados na elaboração de algumas análises sobre as relações entre evasão e outros indicadores. Esses estados são Acre, Amapá, Roraima e Tocantins. 
No Piauí, houve inclusive um caso de evasão negativa, que significa aumento no número de matriculados novos e não ingressantes, podendo ser alunos transferidos, ou que voltaram a estudar, ou, simplesmente, pode ter havido problemas de registro dos dados desses alunos.

Os estados da Bahia e de Sergipe tiveram, também, oscilações e suas médias estão acima das médias da região como um todo e do Brasil. Os demais estados tiveram médias menores que a regional.

O Sudeste, que tem cerca de metade dos alunos de cursos superiores do Brasil, teve uma variação na taxa de evasão anual praticamente igual à do Brasil. Embora tenha crescido em 2003 e 2004, a evasão anual em São Paulo tem-se mantido abaixo da média da Região Sudeste e do Brasil. Minas Gerais, com a exceção de 2002, e Espírito Santo, com a exceção de 200 I, também têm-se mantido com taxas de evasão anual abaixo da média da região e do Brasil. Já o Estado do Rio de Janeiro tem uma das mais altas taxas de evasão do país, em torno dos 33\%, tendo caído ligeiramente em 2005.

As regiões Sul e Centro-Oeste mostram oscilações leves, mas tiveram em quase todo o período taxas pouco maiores que as nacionais.

O Paraná tem a evasão anual mais baixa da Região Sul, e em relação ao Brasil, enquanto Santa Catarina praticamente acompanha o padrão da Região Sul, ligeiramente acima do padrão nacional. $\bigcirc$ Rio Grande do Sul tem a mais alta taxa de evasão da região, acima da média nacional.

Já os estados do Centro-Oeste, Mato Grosso do Sul, Mato Grosso e Goiás, tiveram taxas médias de evasão anual oscilantes. Goiás ficou na média, com uma evasão menor que a regional e a nacional. Mato Grosso e Mato Grosso do Sul tiveram médias ligeiramente acima da regional e da nacional. $\bigcirc$ Distrito Federal, no entanto, tem mantido taxas mais altas que as regionais e nacionais, permanecendo na faixa dos $28 \%$.

\section{ÁREAS DE CONHECIMENTO E ALGUNS CURSOS DE DESTAQUE}

\section{Áreas de conhecimento}

As áreas do conhecimento que constam do trabalho são as que figuram nas sinopses do Inep a partir de 2000: 
I. Agricultura e Veterinária

2. Ciências, Matemática e Computação

3. Ciências Sociais, Negócios e Direito

4. Educação

5. Engenharia, Produção e Construção

6. Humanidades e Artes

7. Saúde e Bem-Estar Social

8. Serviços

A tabela 6 traz a evasão anual média para as oito áreas.

Enquanto o Brasil manteve uma taxa de evasão anual, entre 200 I e 2005, na faixa de 22\%, para a área de Ciências Sociais, Negócios e Direito este índice correspondeu a aproximadamente $25 \%$. Já a taxa de evasão da área de Educação neste período oscilou em torno de $18 \%$, índice relativamente baixo se comparado à média nacional. Com 29\% de média, Serviços é a área que apresentou a maior evasão no período.

Com exceção do resultado do curso de Zootecnia, em 2001 , todos os cursos da área de Agricultura e Veterinária e a própria área como um todo tiveram, no período, uma evasão anual menor que a média nacional. Nessa área a evasão oscila em torno de 17\%. Vale lembrar que essa é a única área em que

TABELA 6

EVASÃO ANUAL MÉDIA POR ÁREA

\begin{tabular}{lcccccc}
\hline Área de conhecimento & 2001 & 2002 & 2003 & 2004 & 2005 & Média \\
\hline Saúde e Bem-Estar Social & 18 & 17 & 20 & 19 & 19 & 19 \\
Agricultura e Veterinária & 17 & 17 & 22 & 16 & 13 & 17 \\
Engenharia, Produção e Construção & 21 & 21 & 22 & 22 & 20 & 21 \\
Ciências, Matemática e Computação & 29 & 27 & 27 & 29 & 28 & 28 \\
Ciências Sociais, Negócios e Direito & 23 & 24 & 25 & 27 & 24 & 25 \\
Educação & 19 & 17 & 16 & 21 & 15 & 18 \\
Humanidades e Artes & 22 & 23 & 23 & 24 & 25 & 23 \\
Serviços & 36 & 24 & 29 & 30 & 28 & 29 \\
Brasil & 22 & 21 & 21 & 24 & 22 & 22 \\
\hline Fonte: Cálculo baseado nos dados do Inep: Sinopses do Ensino Superior - 200l-2005 (Brasil, 2006).
\end{tabular}


há uma predominância das IES públicas, onde as evasões são bem mais baixas que nas privadas.

Pode-se perceber ainda pela tabela 6 que a área de Saúde e Bem-Estar Social tem taxa média de evasão anual variando em torno de 19\%, o que significa a terceira menor taxa entre as oito áreas do conhecimento.

Tanto Engenharia, Produção e Construção como Humanidades e Artes apresentaram índices muito próximos das médias nacionais entre 200 I e 2005. A evasão anual média de Engenharia, Produção e Construção fica ligeiramente acima (23\%) do índice para todo o país, enquanto Humanidades e Artes tem um índice médio infeiror (21\%) ao brasileiro.

Finalmente, a área de Ciências, Matemática e Computação tem uma taxa em torno dos $28 \%$, consideravelmente acima, portanto, da média nacional, abaixo apenas da evasão anual média registrada nos cursos de Serviços.

\section{Cursos de Destaque}

Foram analisados 47 cursos nas oito áreas de conhecimento listadas. A seguir, as tabelas 7 e 8 destacam os dez cursos que apresentaram, respectivamente, as maiores e as menores taxas de evasão em 2005. Nas duas tabelas, entretanto, pode-se acompanhar a evolução das taxas para o período de 200 I a 2005.

Na tabela 7, Matemática lidera a lista das maiores taxas com 44\% de evasão em 2005. Esse valor está acima do que vinha sendo registrado nos últimos quatro anos. Por essa razão, a média para 200 I -2005 fica próxima a 30\%.

Os cursos de Formação de Professores da Educação Básica / Normal Superior vêm em seguida, mas, como pode ser percebido, as taxas verificadas nos anos precedentes variam muito, fato que exige cuidado na interpretação do resultado 3 .

3. Em 200l, os cursos de Formação de Professores da Educação Básica / Normal Superior apresentaram uma taxa de evasão anual negativa (- 46\%), reflexo, certamente, da busca por esse curso que teve um aumento significativo da oferta entre 2000 e 200 I , por conta de uma exigência da Lei de Diretrizes e Bases da Educação - LDB - Lei n. 9.394/96, e que deve ter atraído alunos já formados em outros cursos - ou que mudaram de curso - que não foram 
TABELA 7

CURSOS COM AS MAIORES TAXAS DE EVASÃO EM 2005

\begin{tabular}{lcccccc}
\hline Cursos & 2001 & 2002 & 2003 & 2004 & 2005 & Média \\
\hline Matemática & 24 & 27 & 31 & 25 & 44 & 30 \\
Formação de Prof. da Educação Básica/ & & & & & & \\
Normal Superior & -46 & 17 & 25 & 3 & 38 & 7 \\
Marketing e Publicidade & 34 & 39 & 33 & 33 & 36 & 35 \\
Educação Física & 31 & 28 & 29 & 30 & 34 & 31 \\
Física & 27 & 14 & 21 & 23 & 34 & 24 \\
Administração & 30 & 29 & 30 & 30 & 33 & 30 \\
Processamento da Informação & 39 & 36 & 34 & 39 & 31 & 36 \\
Ciências da Computação & 31 & 31 & 31 & 34 & 30 & 32 \\
Design e Estilismo & 15 & 23 & 14 & 32 & 27 & 22 \\
Jornalismo & 28 & 23 & 25 & 27 & 26 & 26 \\
\hline
\end{tabular}

Fonte: Cálculo baseado nos dados do Inep: Sinopses do Ensino Superior - 200 I-2005 (Brasil, 2006) .

TABELA 8

CURSOS COM AS MENORES TAXAS DE EVASÃO EM 2005

\begin{tabular}{lcccccc}
\hline Cursos & 2001 & 2002 & 2003 & 2004 & 2005 & Média \\
\hline Medicina & 0 & 4 & 8 & 3 & 5 & 4 \\
Formação de Professores de & & & & & & \\
Disciplinas Profissionalizantes & 24 & 19 & 23 & 26 & 7 & 20 \\
Formação de Professores de Matemática & 25 & 18 & 20 & 24 & 7 & 19 \\
Odontologia & 13 & 11 & 12 & 12 & 9 & 11 \\
Pedagogia & 20 & 19 & 7 & 22 & 11 & 16 \\
Agronomia & 13 & 15 & 12 & 15 & 11 & 13 \\
Engenharia Elétrica & 8 & 22 & 25 & 25 & 11 & 18 \\
Formação de Professores de Geografia & 20 & 5 & 16 & 22 & 12 & 15 \\
Geografia & 13 & 12 & 9 & 32 & 12 & 16 \\
Formação de Professores de Biologia & 25 & 23 & 17 & 34 & 13 & 22 \\
\hline
\end{tabular}

Fonte: Cálculo baseado nos dados do Inep: Sinopses do Ensino Superior - 200 I-2005 (Brasil, 2006).

considerados como ingressantes, mas apenas como matriculados. Após esse resultado atípico, o curso passou dois anos com taxas positivas e altas de evasão, para cair de novo em 2004 e chegar a $38 \%$ em 2005, mostrando um comportamento muito inconstante, de modo que a média no período não tem muito significado. 
Ao contrário do observado nos cursos de formação de Professores da Educação Básica / Normal Superior, a taxa de evasão anual dos cursos de Marketing e Publicidade mostra pouca variação no período exposto na tabela 7, o que faz a média dos cinco anos ficar próxima da taxa verificada em 2005.

Vale ainda destacar os cursos de Educação Física cuja taxa anual em 2005 chega à casa dos 34\%, também próxima da média dos anos analisados.

A taxa de evasão dos cursos de Processamento de Informação em 2005 não está entre as cinco maiores, mas quando são levados em conta todos os cinco anos, a taxa de evasão média de Processamento de Informação passa a ser a maior da tabela 7.

Na tabela 8, em que cursos com menores taxas de evasão para 2005 são apresentados, Medicina é o destaque não só pelo valor relativo a 2005, mas também pela média do período.

Ocupando respectivamente o segundo e o terceiro lugar, os cursos de Formação de Professores de Disciplinas Profissionalizantes e de Formação de Professores de Matemática tiveram uma taxa anual de evasão de 7\% em 2005. Entretanto, esse valor está bem abaixo da média dos últimos cinco anos (respectivamente, $20 \%$ e 19\%). Assim, Odontologia - quarta menor taxa em 2005 - chega ao final do período com uma média de $11 \%$, perdendo apenas para Medicina.

\section{CORRELAÇÕES}

\section{Correlação entre evasão e demanda}

A tabela 9 traz, para as áreas do conhecimento analisadas, a evasão anual e a relação candidato por vaga em 2005.

A tabela 9 mostra que as três áreas que tiveram relações candidato por vaga satisfatórias tiveram, também, taxas médias anuais de evasão menores que a nacional ${ }^{4}$ (22\%). São elas: Saúde e Bem-Estar Social, Agricultura e Veterinária, Engenharia, Produção e Construção. A mais alta taxa de evasão, da área de Serviços, corresponde à menor relação "candidato por vaga".

4. Correlações entre evasão e mensalidade também foram calculadas, mas os resultados não foram expressivos. 
TABELA 9

CORRELAÇÃO ENTRE EVASÃO ANUAL E DEMANDA

NO PROCESSO SELETIVO POR ÁREA - 2005

\begin{tabular}{lcc}
\hline Áreas & Taxa de evasão & No de candidatos por vaga $^{\circ}$ \\
\hline Saúde e Bem-Estar Social & 19 & 3,3 \\
Agricultura e Veterinária & 13 & 4,5 \\
Engenharia, Produção e Construção & 20 & 2,5 \\
Ciências, Matemática e Computação & 28 & 2,2 \\
Ciências Sociais, Negócios e Direito & 24 & 1,8 \\
Educação & 15 & 1,6 \\
Humanidades e Artes & 25 & 2,3 \\
Serviços & 28 & 1,3 \\
Brasil & 22 & 2,1 \\
\hline
\end{tabular}

Fonte: Cálculo baseado nos dados do Inep: Sinopse do Ensino Superior - 2005 (Brasil,2006).

Apenas uma área, a de Educação, teve taxa de evasão anual baixa e relação candidato por vaga insatisfatória. Convém lembrar que essa área tem uma participação significativa das IES públicas (45\%). Nos últimos anos, houve uma busca pelos cursos superiores por parte do imenso contingente de formados nos cursos médios de magistério e que procuravam atender à LDB e se habilitar para a participação em concursos públicos promovidos pelos sistemas municipais de ensino.

\section{Comparação do índice de evasão no Brasil e em outros países}

A maioria dos países mede o índice de titulação no ensino superior, que seria o número de formados em um certo ano em relação ao número de ingressantes quatro anos antes, sendo a evasão medida como a diferença desse índice para 100\%.

As tabelas 10, II e 12 trazem os índices de alguns países da América Latina, da Organização para Cooperação e Desenvolvimento Econômico OCDE - e americanos, considerando as diferentes mantenedoras de IES.

Os dados mostram que, quando usamos o índice de evasão total no período de 4 anos em relação aos demais países, o Brasil se assemelha aos 
Estados Unidos, com a inversão entre público e privado, uma vez que lá as IES privadas são as mais prestigiosas e com maior concorrência. As taxas brasileiras ficam um pouco abaixo dos países da América Latina mencionados, que possuem o setor privado de ensino superior desenvolvido; acima dos países orientais citados e no meio termo entre os demais países indicados na OCDE.

TABELA 10

ÍNDICE DE EVASÃO TOTAL MÉDIA DE CURSOS

DE ALGUNS PAÍSES DA AMÉRICA LATINA

\begin{tabular}{lccc}
\hline Países & Pública & Privada & Total \\
\hline Bolívia & - & - & 73 \\
Chile & 50 & 63 & 54 \\
Colômbia & 51 & 51 & 51 \\
Cuba & 25 & - & 25 \\
Uruguai & 72 & 72 & 72 \\
Venezuela & 60 & 43 & 52 \\
Brasil & 33 & 53 & 48 \\
\hline
\end{tabular}

Fonte: Cinda/Unesco, 2006, baseada nos dados do Inep 200 I-2005 para o Brasil (Brasil, 2006).

TABELA I I

ÍNDICE DE EVASÃO TOTAL MÉDIA DE CURSOS

DE ALGUNS PAÍSES DA OCDE - 2005

\begin{tabular}{lc}
\hline Países & Índice de evasão médio \\
\hline Japão & 07 \\
Turquia & 12 \\
UK & 17 \\
Coréia & 22 \\
Alemanha & 30 \\
México & 31 \\
USA & 34 \\
França & 41 \\
Itália & 58 \\
Suécia & 52 \\
\hline
\end{tabular}

Fonte: OCDE, 2006. 
TABELA 12

ÍNDICE DE EVASÃO TOTAL MÉDIA DE CURSOS

DE ALGUNS TIPOS DE IES AMERICANAS

\begin{tabular}{lc}
\hline Tipo de IES & Índice de evasão média \\
\hline Privadas muito seletivas & 16 \\
Privadas seletivas & 35 \\
Privadas abertas & 52 \\
Públicas muito seletivas & 26 \\
Públicas seletivas & 49 \\
Públicas abertas & 68 \\
Colleges privados seletivos & 16 \\
Colleges privados abertos & 59 \\
Colleges públicos seletivos & 58 \\
Colleges públicos abertos & 64 \\
\hline
\end{tabular}

Fonte: ACT, 2005.

\section{CONCLUSÕES}

Entre 200 I e 2005, de acordo com cálculos feitos com base em dados do Inep, a taxa anual média de evasão no ensino superior brasileiro foi de $22 \%$, com pouca oscilação, mas mostrando tendência de crescimento. A evasão anual é maior nas IES privadas, cuja taxa média no período foi de 26\% contra I2\% das IES públicas. Entre as públicas, as municipais respondem pela maior taxa de evasão anual, enquanto as comunitárias e confessionais mostram uma taxa maior que as particulares, entre as privadas.

A taxa de evasão anual verificada nas faculdades foi quase duas vezes maior do que a observada nas universidades e centros universitários.

A Região Norte do país apresentou menor taxa de evasão anual no período, e as demais regiões mostraram taxas quase iguais às nacionais.

Estado do Rio de Janeiro apresentou média de evasão anual relativamente alta, a maior do Brasil, seguido do Distrito Federal, Rio Grande do Sul, Amapá e Rondônia. A menor taxa ocorreu no Estado do Pará, com um valor menor que a metade da taxa nacional. $O$ Pará tem alta porcentagem de alunos em IES públicas. 
Enquanto as áreas de Serviços e de Ciências, Matemática e Computação tiveram as mais altas taxas de evasão anual média, as áreas de Educação, Agricultura e Veterinária e de Saúde e Bem-Estar Social apresentaram as menores taxas.

Entre os cursos, Medicina tem a mais baixa média de evasão anual, de apenas $4 \%$, muito inferior aos cursos subseqüentes de menores taxas. Os cursos da área de Serviços, os ligados à Comunicação Social e os de Processamento da Informação tiveram as mais altas taxas de evasão anual média.

A evasão no ensino superior brasileiro, do ponto de vista macroscópico, guarda alguma correlação, embora não muito significativa, de acordo com este trabalho, com fatores socioeconômicos.

Não é possível afirmar que a situação da evasão brasileira é pior, ou melhor, do que a média dos índices internacionais, que variam muito de país para país. Entretanto, há necessidade de realizar estudos sistemáticos com vistas a reduzir as taxas de evasão e evitar os desperdícios, tanto do ponto de vista social quanto do financeiro.

\section{REFERÊNCIAS BIBLIOGRÁFICAS}

ACT REPORT. National collegiate retention and persistence to degree rates 2005. Disponível em: www.act.org. Acesso em: dez. 2006.

BRASIL. Ministério da Educação. Instituto Nacional de Estudos e Pesquisas Educacionais. Sinopses do ensino superior. Censos do ensino superior. Comunicações pessoais. Disponível em: www.inep.gov.br. Acesso em: dez. 2006.

CENTRO INTERUNIVERSITARIO DE DESARROLLO. Repitencia y deserción universitaria en América Latina. Chile: Unesco, 2006.

HABLEY, W. R. Works in student retention. lowa: ACT Inc., 2004. (GAT, Report)

LOBO, R. A Educação no Brasil: 2006. In: CINDA. Educación superior en Iberoamérica. (No prelo)

ORGANISATION FOR ECONOMIC CO-OPERATION AND DEVELOPMENT. Meeting of OECD educating ministers. Disponível em: www.oecd.org. Acesso em: dez. 2006.

Recebido em: janeiro 2007

Aprovado para publicação em: fevereiro 2007 